\section{A FEW OBSERVATIONS ON THE PATIIOLOGY AND TREATMENT OF MIGRAINE.}

BY W. PEMBERTON PEAKE, M.R.C.S., L.R.C.P., SURGEON TO TIE LEIC'SSTER P'ROVIIENT DISPENSARY.

No more appropriate description of this distressing complaint could be given than the term "nerve-storm," it being one of that class of nervons diseases class ed under the head of the "paroxysmal neuroses," and the observation of several cases only points out how widely different is the aspect of each case and how utterly useless is anything in the shape of empirical treatment. It is well known how an attack of migraine commences : first a small portion of the field of vision is obscured, generally about the centre ; this small patch grows larger and larger, and works its way from the centre of the field to one side or other. The blurred patch is replaced by waving, zigzag lines, slightly luminous, and which can be observed whether the eyes are open or shut. These symptoms gradually wear off, and the patient vainly believes his attack is over. This $I$ shall venture to call the first stage, in contradistinction to the headache, or second stage ; and before going on to describe the second stage I would venture to mention some rather remarkable variations of the first stage. I believe that the phenomena of the first stage are by no means limited to the visual organs, but may occur in any of the organs of special sense. Several writers have remarked a tingling of the fingers accompanying the visual derangement, but I have met more than one case in which such tingling preceded the headache stage when no visual symptoms were noticed. This tingling occurred along the ulnar border of the hand, and completely passed off before the headache set in. Another most remarkable case I saw in Durham, and it was that of a patient who complained of loud buzzing noises in the ears, followed by severe headache. I at once thought of quinine or salicine, but the patient denied having taken any medicine. I next examined both ears carefully and found nothing wrong, so I put it down as a case of migraine, and treated it as such with success. The taste I have never found alone affected, though I do not doubt that it is, and is unobserved; but $I$ have met three or four patients who, when the visual symptoms are on, fail to taste tobacco smoke when smoking or to smell it. The second stage comes on gradually after the first stage has entirely passed off, and consists of a gradually increasing neuralgia, generally in the supra orbital or auriculo-temporal nerves. The neuralgia is glways limited to the nerves on one side, and, as far as I have observed, always on the opposite side to which the field of vision was affected. The headache, or rather neuralgia, increases in intensity till a maximum is reached, and then diminishes till the "storm" is over and the patient is as he was before. Another prominent symptom of the second stage is gastric derangement, and some authors state that sickness generally brings the attack to an end; but $I$ have found that sickness is only present in one out of eight cases, although nausea was present in them all. It is unnecessary to say that there is a complete repugnance to food during the whole of the second stage. The pathology of migraine has been a matter of considerable doubt for some time. That it is a vaso-motor change is generally recognised, but I cannot help thinking that the first and second stages of the complaint are due to different states of the vessels in such portion of the optic thalamus, or wherever the seat may be, and $I$ am driven to this conclusion by the wide difference in the symptoms of the two stages. If the temporal artery be felt in the first stage it is found to be small, hard, and wiry, while in the second stage it is dilated and throbbing. Again, pressure on the internal carotid makes no difference to the symptoms of the first stage, but in the second stage it almost completely stops the headache, and again, a glance at the dises in the two stages shows a marked difference. In the first stage they are nearly normal, but I have more than once observed a contraction of the vessels, while in the second stage the discs are suffused and the vessels dilated, and their pulsations clearly visible.

These observations lead me to agree with the theory put forth by Dr. Latham in 1872 , that migraine is due to cerebral anæmia, followed by a supervening hyperæmia The treatment takes two forms-first, the preventive treatment; secondly, the immediate treatment. The preventive treatment compels a close inquiry into the patient's babits and mode of living. Dysuepsia has long been recognised as an important cause, and constipation is equally important. Another cause as common as either of these is over-exertion of the eyes or an irregularity in the vision of the two Over-exertion caused by reading too much or contracting the eyes to accommodate for small print is frequently over looked. I believe the sixpenny novel has many thousands of attacks of migrnine to account for. Again, it is highly important to observe, if possible, the position of the patient while reading, for most people generally settle down in position which aflords as much light as possible to fall on the top of their heads, while very little falls on the book they may be reading. Railway travelling causes many attacks of migraine, and patients who are subjects of it should be recommended to keep their eyes shut for at least part of their journey. Change of scene is another cause probably resulting from over-exertion of the eye; I have known two or three patients who positively dread the first week of their holiday on account of the inevitable attank of migraine which is sure to come on. Certain drugs cause attacks of migraine, and the most important are nux vomica and strycbnine, cinchona and quinine, and salicylate of soda. I know cases in which ten minims of the tincture of nux vomica invariably brought on an attack, and one case in which the drug was given in the hope of it working a cure. The immediate treatment is very important, as one little item left out may spoil the whole effect of the drugs. I have found only two drugs to have any effect, and those are guarana and antipyrin, and they must be given at the commencement of the attack, or they are useless. Of the two I prefer the first-guarana for although it does not work with the rapidity of antipyrin it is more certain in action. The difficulty with antipyrin is to find the exact dose to suit the patient. I remember one case-a doctor, who immediately an attack came on took twenty grains of antipyrin, but never seemed to gain any benefit therefrom. I recommended him to try ten grains instead, and the result was marked, the second stage being entirely absent, although there was prostration from the drug. And this is another objection to antipyrin: if it does not do good it makes the patient much worse, for it is most depressing at a tinse when the patient is most depressed.

My treatment of an attack is as follows. Immediately the symptoms of the first stage come on the patient should cease all work, should take twenty grains of guarana, and fill his stomach with beef-tea or broth, and then lie down and, if possible, sleep the whole attack through; but if unable to sleep, he should rest till the end of the first stage, and then a cup of strong tea should be given; and during the second stage it is generally important that the mind should be occupied by conversation or light study, as dwell ing on the pain of the headache makes it many times worse. By this treatment the second stage is usually averted, and if it does ensue it is transitory, and hardly noticeable.

Leicester.

\section{Clinital a dotes:}

MEDICAL, SURGICAL, OBSTETRICAL, AND THERAPEUTICAL.

THE TRUE NATURE OF SUBUNGUAL EXOSTOSIS OF THE GREAT TOE.

By W. Roger WilliaMs, F.R.C.S., SURGEON TO THE WESTERN GENERAL DISPENSARY, LATE SURGICAL REGISTRAR TO THE MIDDLESEX HOSPITAL.

Some time ago, after careful study of a considerable number of cases of this interesting disease, I came to the conclusion that these tumours differed from other exostoses in several important particulars; and that their peculiarities could only be accounted for by regarding the tumour as due to overgrowth of the rudiment of a supernumerary toe. The reasons that led me to this conclusion were briefly these: (1) The frequency with which the disease affects the great toe, for I have met with only a single instance of it on any other. (2) The extraordinary constancy with which the tumours arise from the tibial side of the terminal phalanx. I have never seen a tumour of this kind con- 
mected with any other part of the phalanx. (3) The structure of the tumour itself, which is not merely that of a cancellous exustosis as it is nsually described. The tunour is a real outgrow th from the phalanx, consisting externally of cortex and internally of cancellous tissue, both of which are directly continuous with the corresponding structures of the phalanx. The fibro-cartilaginous matrix which caps the tumour man, I think, be regarded as the remains of the original rudiment. The following considerations tend to support this view of the question and to give the subject greater dofinition. In the foot most cases of polydactylism occur in connexion with the great toe. In these cases there is, as a rule, only a single extra digit, and in the slightest degree of the malformation the affected part is simply bifid at the extrenity. The supernumerary part is always placed on the tibial side of the great toe. Casespresent ing several supernumerary digits probably belong to a different category-that is to say, they are examples of incomplete duplicity of the whole extremity. The pentadactylous type of pes prevails widely among vertebrates. There are, however, good reasons for believing that this type has been volved from a more primitive one, possessing at least six digits (hexadactylous); by the more or less complete abortion of a digit, the pre-hallux, from its tibial side. ${ }^{1}$ We were, however, unacquainted with any airbreathing vertebrate actually possessing such characters until Marsh published his description of Sauranodon in $1880 .^{2}$ The anterior and postcrior limbs of this creature, which functioned as paddles, possess six complete digits. The rudiment of a sixth toe has been observed on the tibial side of the pes of several five-toed amphibians, in reptiles, and in many mammals. I liave a dog with six digits on the extremity of the right forelimb, of which the two inner ones are rudimentary, but have well-developed nails. On this subject Wiedersheim remarks:" "In human embryos of the second month a distinct cartilage is present on the tibial side of the taraus, and this probably answers to a small bone on the tibial border of the foot of monotremes, American marsupials, edentates, carnivores, rodents, in sectivores, and monkeys. This most likely corresponds to an extra-first toe (pre-hallux of Bardeleben)." Thus, as Dr. Cowper has pointed out, there is sufficient evidence to show that pentadactylous vertebrates have more or less completely lost a digit from the tibial side of the pes, and that this lost digit (the pre-hallux) occasionally reappears, with varying degrees of incompleteness, in consequence of reversion. Bardcleben maintains that the ancestors of modern mammals were heptcedactylous, and that they have lost a digit from the post-axial as well as from the pre-axial side of the foot. I think the eridence here adduced is sufficient to warrant me in associating the subungual exostosis of the great toe with the rudiment of this lost prehallux in its least complete form.

Welbeck-street, $\mathrm{w}$.

\section{TWO CASES OF CHOREA DEPENDENT UPON THE PRESENCE OF INTESTINAL WORMS.}

By Thomas W. Jenkivs, M.D.

THE following cases are not without interest. The first is probably unique in that the subject of it has had two attacks of chorea within twelve months, a similar cause operating on both occasions.

CASE l.-John H—, aged four, of fair growth and previously healthy, except for an attack of measles and a very severe attack of scarlet fever, from both of which he recovered without sequelæ, was first seen on March 30th, 1889. For several days previously his parents had noticed awkwardness in his walk and uncertainty in the use of his right hand. I found considerable erratic, jerking movements of right hand, arm, and leg. Left side unaffected. Occasional slight twitching of right side of face. Tongue, when protruded, in constant motion. Heart sounds normal. On April 4th there was increased violence of movements, still unilateral. Heart irregular in rhythm and force. Kespiration also irregular, both in frequency and in depth, and quite independent of cardiac irregularity. On the afternoon of the th patient complained of sickness and vomited several times

1 Journal of Anatomy, vol. xxiii., p. 242 et seq

3 Comparative Anatomy of Vertelmates, English translation, p. 10 . during the night. Choreic movements very violent. On the morning of the 5 th he vomited a round worm about $12 \mathrm{in}$. long. In the forenoon he received a teaspoonful of oil of turpentine, which was immediately vomited. A second teaspoonful given an hour later was also rejected. In the evening a third teaspoonful was arlministered and retaincd. Next morning a strong dose of senna resulted in active purgation, which brought away a large number of round worms of all sizes. When seen in the afternoon, patient was calm and collected, only very slight movements being detected. Heart sounds and action normal. On the 10th, after a dose of senna, a small dead worm was discharged. On the 12 th the patient was perfectly well.

In March of this year a second attack occurred. Choreic movenents were again observed. Oil of turpentine was again administered, and a large number of thread-worms was voider. After a few days the patient had completely recovered.

CASE 2.-W - harl chorea when twelve years of age After a twelvemonth's suffering, during which time many drugs had been employed, he was sent to Leith for " change of air." Shortly after arrival there the choreic movement. became very violent. Oil of turpentine was administered, with the result that a number of round worms was discharced. After a few days the patient returned home well.

CASE 3.-B-, a girl aged eleven. This case was of a different nature from the foregoing. During the development of an abscess in the mastoid cells chorea supervened. As soon as the abscess was opened the chorea ceased.

These cases prove conclusively that chorea may be caused by various forms of peripheral irritation. Whifflet, N.B.

\section{A CASE OF BIFID IMPERFORATE ANUS, WITH DEFICIENCY OF THE RECTUM.}

By Fred. EdGe, F.R.C S. ENG., B.S., M.B. Lond. RESIDENT MEDIC.AL OFFICER, ST. MARY'S HOSPITAL, MANCHESTER.

A MALE child, three days old, was brought to the hospital. Since birth nothing had passed per anum. Castor oil had been given more than once, and the child had vomited repeatedly and was in great distress. On examining I found the abdomen distended. There was an anal depression, which was divided into two by a median septum continuous in front with the raphe of the perineum. Both divisions ended blind. On compressing the abdomen the pelvic floor was caused to project rather freely, thus demonstrating the probability of the extension of the rectum into the pelvic cavity. I determined to dissect down upon the rectum, to open it and to stitch the margins of the rectal opening to the edges of the perineal incision. My colleague, Mr. Baxendell, kindly gave chloroform, and assisted me. Having passed a sound into the bladder, I made a crucial incision over the anus. I dissected carefully in front of the sacrum, and having found the rectum I opened it. Meconium escaped freely. I then tried to suture the rectum to the skin; but it was so high that I could not bring them together, so I approximated them with a few sutures, thus leaving a dangerous uncovered surface of tissue. The parts were dusted with iodoform and a simple (Iressing of lint applied. The child remained in the hospital three days and progressed favourably, the wound looking healthy. It was then taken home by its mother. It grew woree day by day, and died on the tenth day after operation. There was no cellulitis about the wound or other sign of inflammatory mischief, but the body was in a filtby condition and very emaciated.

The chicf point of interest in the case, apart from its adding another to the long list of unsuccessful cases, is the bifid condition of the anal depression or proctodeum. From my reading I find nothing pointing to the possibility of the proctodeum ever being a double involution. It seems probable that the tendency to union, which causes the closure of the genital cleft and produces the raphe of the perineum. had been carried backwards to the embryonic cells of the anal site, and thus produced the median septum. Perhaps I may be allowed to say that in another similar case I should feel justified in dissecting more widely and in using more traction to bring the presenting bowel down to the perineal surface. Because if this is not done, the track intervening between the bowel and the surface will become a mere strictured sinus. Manchestcr. 